\title{
Tumor Necrosis Factor Stimulates Amino Acid Transport in Plasma Membrane Vesicles from Rat Liver
}

\author{
Anthony J. Pacitti, Yoshifumi Inoue, and Wiley W. Souba \\ Departments of Surgery, Biochemistry/Molecular Biology, and Physiology, University of Florida, Gainesville, Florida 32610
}

\begin{abstract}
Severe infection is characterized by a translocation of amino acids from the periphery to the liver, an event that is mediated in part by cytokines such as tumor necrosis factor- $\alpha$ (TNF). We investigated the activities of $\mathrm{Na}^{+}$-dependent transport systems A, ASC, and $\mathbf{N}$ in hepatic plasma membrane vesicles (HPMVs) prepared from rats treated with TNF in vivo. TNF did not alter sodium uptake but resulted in time- and dose-dependent fivefold and $50 \%$ maximal increases in system $A$ and system $\mathbf{N}$ activity, respectively, in HPMVs secondary to an increase in the transport $\mathrm{V}_{\max }$. Maximal increases in transport were observed $4 \mathrm{~h}$ after exposure to TNF and had returned to basal levels within $24 \mathrm{~h}$. Similarly, system ASC activity was stimulated $80 \%$ in HPMVs from rats treated with TNF. Incubation of HPMVs from normal rats in vitro with TNF did not alter transport activity. Pretreatment of animals with the glucocorticoid receptor antagonist RU 38486 attenuated the TNFinduced enhancement in transport activity by $50 \%$. The marked increase in $\mathrm{Na}^{+}$-dependent amino acid transport activity by TNF is mediated in part by the glucocorticoid hormones and represents an important mechanism underlying the accelerated hepatic amino acid uptake that occurs during critical illness. $(J$. Clin. Invest. 1993.91:474-483.) Key words: cytokines • sepsis • glucocorticoids • amino acid transport • liver • tumor necrosis factor
\end{abstract}

\section{Introduction}

States of critical illness, such as severe injury and infection, result in a spectrum of systemic metabolic alterations that are carefully orchestrated in a prioritized fashion. A central feature of the acute-phase response to infection is the mobilization of amino acids from the periphery and the concomitant marked increase in amino acid uptake by the liver $(1,2)$. This accelerated hepatic uptake supports hepatic gluconeogenesis and acute-phase protein synthesis and appears to be a crucial determinant conferring a survival advantage to the host $(1,3)$. Cytokines, potent polypeptide substances elaborated by the hosts' own cells in response to bacteremia, endotoxemia, and other insults, are thought to mediate and/or initiate many if not all of the physiological alterations during sepsis $(4,5)$. Tumor

Address reprint requests to Dr. Wiley W. Souba, Department of Surgery, P.O. Box 100286, University of Florida, Gainesville, FL 326100286. 1992.

Received for publication 4 May 1992 and in revised form 25 August

J. Clin. Invest.

(C) The American Society for Clinical Investigation, Inc.

$0021-9738 / 93 / 02 / 0474 / 10 \$ 2.00$

Volume 91, February 1993, 474-483 necrosis factor- $\alpha$ (TNF) ${ }^{1}$ has been strongly implicated in this capacity $(4,6,7)$ and is the cytokine that has been most extensively studied.

Several factors may contribute to an increase in the net uptake of substrate by an organ (e.g., an increase in organ substrate delivery or activation of intracellular metabolism). However, in the case of amino acid metabolism, it has become increasingly apparent that the regulated activity of the membrane proteins catalyzing the selective transport of amino acids plays a major mechanistic role in such alterations (8). Several distinct amino acid transport systems have been identified and characterized in the liver, and their regulation has been investigated, including the $\mathrm{Na}^{+}$-dependent systems $\mathrm{A}, \mathrm{ASC}$, and $\mathrm{N}$ (9-11). Recently, because of their key role in regulating metabolic processes, studies have begun to examine the effect of cytokines on hepatic amino acid transport, with reference primarily to that of system A (12-18). However, few studies have focused their investigation directly at the cellular or membrane level and no information is available concerning cytokine modulation of hepatic carrier-mediated amino acid transport apart from that of system A. In the present study, to investigate cytokine modulation of hepatic amino acid transport at the cellular level, we employed isolated hepatic plasma membrane vesicles (HPMVs) to examine the activity of the major $\mathrm{Na}^{+}$-dependent transport systems catalyzing the concentrative transfer of amino acids into the liver after in vivo administration of TNF.

\section{Methods}

Adult male Sprague-Dawley rats weighing 150-210 g were obtained from Harlan Sprague Dawley, Inc. (Indianapolis, IN) and used for the present investigations. Animals were housed in the animal care facility under standard conditions (i.e., 12-h light-dark cycles and access to standard rat chow and water ad libitum). Before study, rats were separated into two groups. One group received a single intraperitoneal injection of TNF $(50,150$, or $450 \mu \mathrm{g} / \mathrm{kg}$ body wt in $<1 \mathrm{ml}$ of $1.0 \mathrm{mg} / \mathrm{ml}$ BSA, $n=14)$. The other group received an equivalent volume of BSA vehicle (control; $n=14$ ). Subsequent studies were performed 2, 4, and $24 \mathrm{~h}$ after intraperitoneal injection. All animals were fasted overnight before the morning of killing. Recombinant TNF was provided as a gift from Patricia Olson, Ph.D., Chiron Corp. (Emeryville, CA). Experiments were approved by the Committee for the Use and Care of Laboratory Animals at the University of Florida.

To evaluate the effects of TNF on hepatic amino acid transport more directly, studies were also done in vitro using HPMVs prepared from normal rats. The vesicle studies consisted of incubating HPMVs with two different concentrations of TNF, IL-1, and IL-6 (100 and $1,000 \mathrm{U} / \mathrm{ml}, 1 \mu \mathrm{g}=\sim 3 \times 10^{5} \mathrm{U}$ ) for $1 \mathrm{~h}$. After this incubation, the transport of radiolabeled amino acids was assayed as described below. IL-1 and IL-6 were purchased from Sigma Chemical Co. (St. Louis, MO).

1. Abbreviations used in this paper: $\mathrm{BCH}, 2$-amino[2,2,1]-heptanedicarboxylic acid, HPMV, hepatic plasma membrane vesicles; MeAIB, $\alpha$-(methylamino) isobutyric acid; TNF, tumor necrosis factor. 
Additional studies were done using the glucocorticoid antagonist RU 38486 to examine the role of the glucocorticoid hormones as regulators of amino acid transport after TNF treatment (see details below).

Preparation of liver plasma membrane vesicles. HPMVs were prepared by Percoll density gradient centrifugation according to Prpic et al. (19) with minor modifications that we have described in detail elsewhere (20). Briefly, at various time points after TNF treatment, livers were excised and perfused with ice-cold PBS ( $150 \mathrm{mM} \mathrm{NaCl}, 10$ $\left.\mathrm{mM} \mathrm{Na}_{2} \mathrm{HPO}_{4}, \mathrm{pH} \mathrm{7.4}\right)$ and homogenized in SEB ( $250 \mathrm{mM}$ sucrose, 1 mM EGTA, 10 mM Hepes, pH 7.5) using a Dounce homogenizer by 10 strokes with a loose-fitting pestle followed by 4 strokes with a tighterfitting pestle. The homogenate was diluted to $6 \%$ (wt/vol) with SEB, centrifuged at $150 \mathrm{~g}$ for $2 \mathrm{~min}$ to remove gross particulate matter, and the resultant supernatant was centrifuged at $1,464 \mathrm{~g}$ for $10 \mathrm{~min}$. The crude pellet was filtered, added to $13.7 \mathrm{ml}$ Percoll (Pharmacia Inc., Piscataway, NJ), and brought to a final volume of $115 \mathrm{ml}$ with SEB (11.9\% vol/vol final [Percoll]). The suspension was thoroughly mixed and centrifuged at $34,540 \mathrm{~g}$ for $30 \mathrm{~min}$. Plasma membrane bands were harvested, pooled, diluted 1:6 ( $\mathrm{vol} / \mathrm{vol}$ ) with SMB ( $250 \mathrm{mM}$ sucrose, 1 $\mathrm{mM} \mathrm{MgCl}, 10 \mathrm{mM}$ Hepes, $\mathrm{pH} 7.5$ ), and washed free of Percoll via a second centrifugation. Membrane pellets were resuspended in SMB and to an approximate protein concentration of $8-10 \mathrm{mg} / \mathrm{ml}$ and aliquots were stored at $-70^{\circ} \mathrm{C}$ in cryotubes (InterMed; Nunc, Roskilde, Denmark) until studied. Vesicle purity was evaluated biochemically by assaying the relative enrichment or impoverishment in the specific activity of the marker enzymes 5'-nucleotidase (21), glucose-6-phosphatase (22), and NADPH/cytochrome $c$ reductase (23). Inorganic phosphate was measured according to Fiske and Subbarow (24).

Vesicle amino acid transport assay. Amino acid transport by HPMVs was evaluated by a rapid mixing/filtration technique described previously (20). Transport assays were undertaken in the absence or presence of sodium except where indicated. Uptake was initiated by mixing $20-\mu \mathrm{l}$ vesicles ( $100-120 \mu \mathrm{g}$ membrane protein) with 20 $\mu \mathrm{l} \mathrm{Na}{ }^{+}$- or $\mathrm{K}^{+}$-uptake buffer containing amino acid tracer in $12 \times 75$ $\mathrm{mm}$ polystyrene tubes using an electronic timer/vortexer apparatus. Final concentrations in the reaction mixture were $100 \mathrm{mM} \mathrm{NaCl}$ or $\mathrm{KCl}, 1 \mathrm{mM} \mathrm{MgCl}, 10 \mathrm{mM}$ Hepes ( $\mathrm{pH} 7.5$ ) and varying concentrations of test amino acid depending upon the experiment. Amino acid uptake was terminated by the addition of $1 \mathrm{ml}$ ice-cold PBS followed by immediate low pressure vacuum filtration of the mixture through a $0.45-\mu \mathrm{m}$ nitrocellulose filter to separate intravesicular from extravesicular amino acid. The filter was rapidly washed twice with a total of $7 \mathrm{ml}$ ice-cold PBS and dissolved in $10 \mathrm{ml}$ Aquasol (New England Nuclear, Boston, MA) for determination of trapped radioactivity by scintillation counting (Beckman LS 7800; Beckman Instruments, Inc., Palo Alto, CA). All transport assays were carried out at $22^{\circ} \mathrm{C}$. With the exception of uptake time courses, transport was terminated at the 10-s time point to insure measurement of initial rates under these assay conditions. L- $\left[\mathrm{G}-{ }^{3} \mathrm{H}\right]$ glutamine and $\mathrm{L}-\left[4,5-{ }^{3} \mathrm{H}\right]$ leucine were purchased from Amersham Corp. (Arlington Heights, IL), $\left[{ }^{3} \mathrm{H}\right]$ MeAIB was obtained from American Radiolabeled Chem. Inc., (St. Louis, $\mathrm{MO}$ ), and L- $\left[{ }^{35} \mathrm{~S}\right]$ cysteine was obtained from New England Nuclear.

System $\mathrm{A}$ and system $\mathrm{N}$ activity were operationally defined as the $\mathrm{Na}^{+}$-dependent transport of $\alpha$-(methylamino)isobutyric acid (MeAIB) and glutamine, respectively. System ASC activity was defined as the $\mathrm{Na}^{+}$-dependent transport of cysteine in the presence of 10 mM MeAIB. The $\mathrm{Na}^{+}$-dependent component of amino acid transport was calculated by subtracting uptake in the presence of potassium ( $\mathrm{Na}^{+}$-independent uptake, triplicate or quadruplicate determinations) from that observed in the presence of sodium (total uptake, quadruplicate determinations). Where indicated, the $\mathrm{Na}^{+}$-dependent uptake of 50 to $100 \mu \mathrm{M}$ assay concentrations of MeAIB, glutamine, and cysteine was evaluated in the presence or absence of a $10-\mathrm{mM}$ excess of unlabeled MeAIB to competitively block any system A-mediated transport component. All experiments examining cysteine transport were performed in the presence of $5 \mathrm{mM}$ DTT to maintain cysteine in the reduced form. Transport kinetic characteristics were determined by assaying uptake as described above and varying the initial concentra- tion of amino acid from $25 \mu \mathrm{M}$ to $10 \mathrm{mM}$. Kinetic experiments were performed at the 10-s time point under initial rate conditions. Carriermediated $\mathrm{Na}^{+}$-independent leucine transport was evaluated by assaying uptake in the absence of sodium and in the absence and presence of a $10 \mathrm{mM}$ excess of $\alpha$-amino [2,2,1]-heptanedicarboxylic acid ( $\mathrm{BCH})(\mathrm{a}$ selective system $L$ substrate). Saturable carrier-mediated leucine transport was calculated by subtracting nonsaturable uptake (defined as that component of uptake resistant to inhibition by $10 \mathrm{mM} \mathrm{BCH}$ ) from total $\mathrm{Na}^{+}$-independent uptake (uptake in the absence of $\mathrm{BCH}$ ). Carrier-mediated $\mathrm{Na}^{+}$-independent glutamine transport was similarly determined with the exception that the nonsaturable component was evaluated in the presence of a $10 \mathrm{mM}$ excess of glutamine rather than $\mathrm{BCH}$.

Osmotic adjustments for varying concentrations of test amino acids and/or inhibitors were made with sucrose where appropriate. In all transport experiments blank values (no vesicles present) were determined and subtracted from the corresponding amino acid uptakes. Membrane protein was determined by a modified Lowry method (25) and all uptakes were normalized to protein. Transport velocities and kinetic parameters were determined from uptake data by nonlinear-regression analysis using a computer software program. Data are expressed as $\mathrm{Na}^{+}$-dependent or $\mathrm{Na}^{+}$-independent velocity in $\mathrm{pmol} / \mathrm{mg}$ protein per unit time.

Transport of sodium by HPMVs. Uptake of radiolabeled sodium by HPMVs was measured by a rapid mixing/filtration technique as described previously for amino acid uptake (20). All incubations were performed at $22^{\circ} \mathrm{C}$ and were initiated by addition of $20 \mu \mathrm{l}$ of vesicle suspension to $20 \mu \mathrm{l}$ of incubation medium. Radiolabeled sodium $\left({ }^{22} \mathrm{Na}^{+}\right)$was purchased from New England Nuclear. Final concentrations in the reaction mixture were: $100 \mathrm{mM} \mathrm{NaCl}, \operatorname{tracer}{ }^{22} \mathrm{Na}^{+}, 1 \mathrm{mM}$ $\mathrm{MgCl}_{2}$, and $10 \mathrm{mM}$ Hepes ( $\mathrm{pH} \mathrm{7.5}$ ). The reaction was stopped at 2.5, 5 , and $10 \mathrm{~s}$.

Studies with the glucocorticoid antagonist $R U$ 38486. To examine the role of the glucocorticoid hormones in the TNF-induced increase in $\mathrm{Na}^{+}$-dependent amino acid transport, rats receiving TNF were pretreated with the glucocorticoid antagonist RU 38486 (a gift from Roussel Uclaf, Romainville, France). Animals received one of four treatments: BSA vehicle (controls), TNF alone, RU 38486 (10 mg/kg) $2 \mathrm{~h}$ before receiving TNF $(150 \mu \mathrm{g} / \mathrm{kg})$, or RU vehicle $2 \mathrm{~h}$ before TNF ( 150 $\mu \mathrm{g} / \mathrm{kg})$. The RU 38486 was administered as a suspension in an aqueous solution of $0.25 \%$ carboxymethylcellulose (Sigma Chemical Co.) and $0.20 \%$ polysorbate (Sigma Chemical Co.) orally by gavage (26). As stated above, a separate group of rats received a corresponding volume $(0.5 \mathrm{ml} / 100 \mathrm{gm}$ body $\mathrm{wt})$ of vehicle orally by gavage. HPMVs were prepared $4 \mathrm{~h}$ after TNF administration and $\mathrm{Na}^{+}$-dependent amino acid transport was assayed.

Statistical analysis. Data were analyzed by either Student's $t$ test or analysis of variance where appropriate followed by Fischer leastsquares difference test if a significant $F$ value was obtained. The level of significance was set at $P \leq 0.05$.

\section{Results}

Assessment of HPMV integrity. Previous reports from this laboratory have documented the plasma membrane vesicular nature and functional reliability of our vesicle preparations in terms of their capacity for time- and concentration-dependent carrier-mediated accumulation of amino acids, enrichment in plasma membrane, and electron microscopic appearance (20). In the present report, the specific activity of selected marker enzymes from multiple control and TNF-treated rat vesicle preparations were measured to evaluate vesicle enrichment in plasma membrane and impoverishment in endoplasmic reticulum. Vesicles from control and TNF-treated rats were enriched 13.3- and 12.7-fold in the specific activity of the plasma membrane enzyme marker 5'-nucleotidase, respectively, over the crude liver homogenates (control, $1.48 \pm 0.27 \mu \mathrm{mol} / \mathrm{mg}$ pro- 

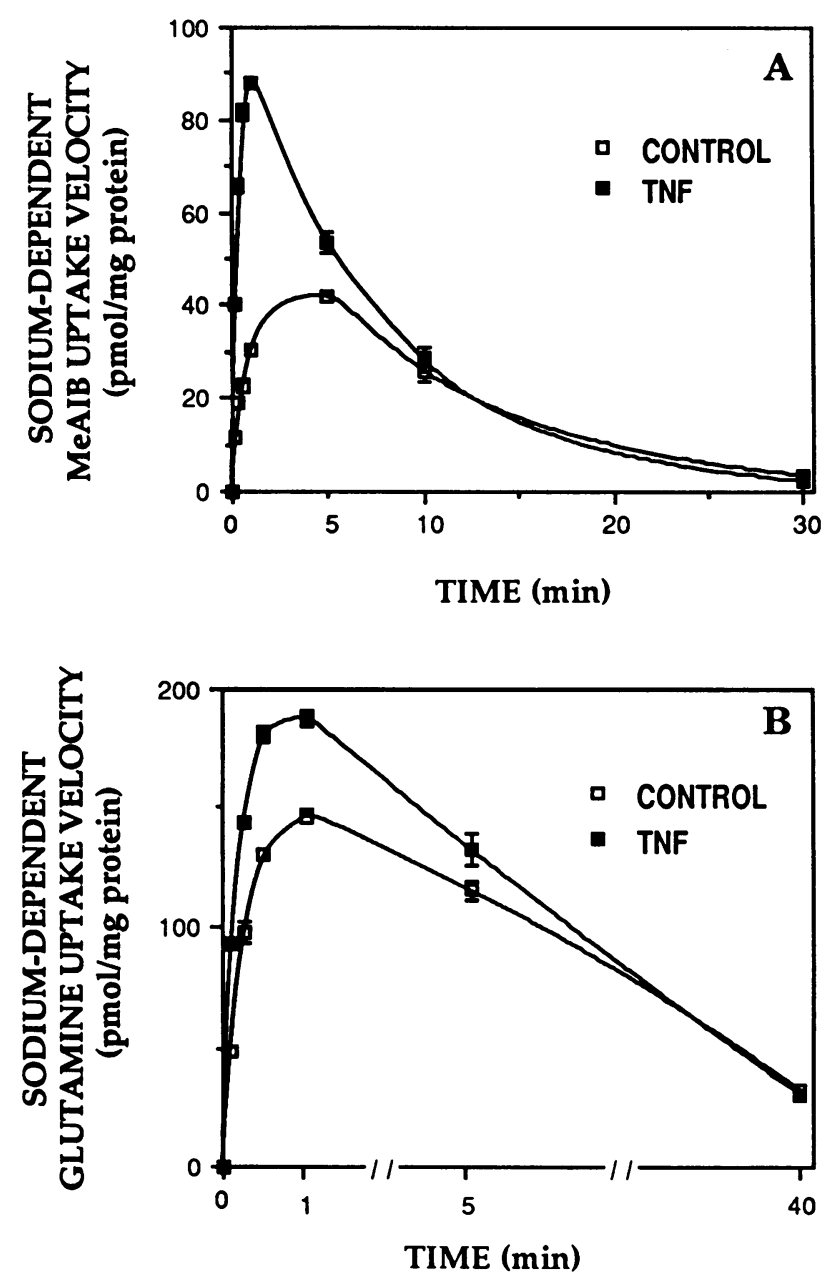

Figure 1. Time course of $\mathrm{Na}^{+}$-dependent amino acid transport by HPMVs prepared from control and TNF-treated rats. Rats were treated with vehicle (control) or TNF $(150 \mu \mathrm{g} / \mathrm{kg})$ and HPMVs were prepared $4 \mathrm{~h}$ later. The $\mathrm{Na}^{+}$-dependent uptake of $50 \mu \mathrm{M}\left[{ }^{3} \mathrm{H}\right] \mathrm{MeAIB}$ $(A)$ or $100 \mu \mathrm{M}\left[{ }^{3} \mathrm{H}\right]$ glutamine $(B)$ was determined as a function of time as described in Methods. Representative time courses from multiple experiments are shown. Each data point is the mean \pm SEM of quadruplicate determinations and error bars not apparent lie within the symbol.

tein per h in homogenate vs. $19.68 \pm 3.34$ in vesicles, $P<0.005$; TNF, $1.73 \pm 0.53 \mu$ moles $/ \mathrm{mg}$ protein per hr in homogenate vs. $21.99 \pm 2.34$ in vesicles, $P<0.005$ ). Concomitant with the marked enrichment in plasma membrane, preparation of vesicles from both control and TNF-treated rats did not result in an enrichment of the microsomal membrane fraction as evidenced by 22 to $33 \%$ impoverishments in the specific activity of the enzyme markers glucose-6-phosphatase and NADPH/ cytochrome $c$ reductase relative to the crude homogenates. Regression analysis of uptake data from kinetic studies demonstrated that vesicles prepared from control or TNF-treated animals exhibited similar permeability coefficients (MeAIB, $217 \pm 36$ for control vs. $222 \pm 34 \mathrm{nl} / \mathrm{mg}$ protein per $10 \mathrm{~s}$ for TNF; glutamine, $105 \pm 7$ for control vs. $107 \pm 12 \mathrm{nl} / \mathrm{mg}$ protein per $10 \mathrm{~s}$ for TNF).

Effects of TNF on amino acid transport in HPMVS. A representative time course of $\mathrm{Na}^{+}$-dependent MeAIB and glutamine transport by vesicles prepared from control rats or rats

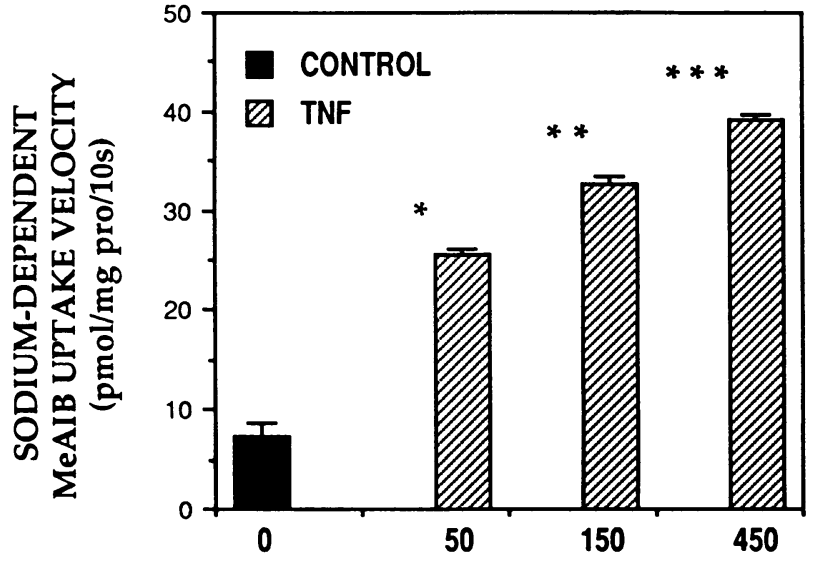

TNF DOSE $(\mu \mathrm{g} / \mathrm{kg} \mathrm{BW})$

Figure 2. Dose-response to TNF of system A-mediated MeAIB transport. Rats were treated with vehicle (control) or the indicated dose of TNF. HPMVs were prepared $4 \mathrm{~h}$ later and the 10 -s $\mathrm{Na}^{+}$-dependent uptake of $50 \mu \mathrm{M}\left[{ }^{3} \mathrm{H}\right] \mathrm{MeAIB}$ by vesicles was determined as described in Methods. $P<0.001{ }^{*}$ vs. Control, ${ }^{* *}$ vs. $50 \mu \mathrm{g} / \mathrm{kg}$, $* * *$ vs. $150 \mu \mathrm{g} / \mathrm{kg}$.

treated with $150 \mu \mathrm{g} / \mathrm{kg}$ TNF for $4 \mathrm{~h}$ is shown in Fig. 1. Accumulation of amino acid by HPMVs occurred in a time-dependent manner, was rapid, and was linear for the initial 30-60 s. Uptake was stimulated and exhibited classic overshoots in the presence of sodium. Prior treatment of animals with TNF resulted in an accelerated uptake of MeAIB by vesicles than that observed in the control condition (Fig. $1 A$ ). The initial (10-s) $\mathrm{Na}^{+}$-dependent MeAIB uptake rate was nearly fourfold greater and peak accumulation at $1 \mathrm{~min}$ was still twice that observed for control vesicles at $5 \mathrm{~min}$. At $1 \mathrm{~min}, \mathrm{Na}^{+}$stimulated MeAIB uptake in vesicles from control and TNF-treated animals by 1.6- and 2.7-fold, respectively, relative to uptake observed in the absence of sodium.

In general, the activity of glutamine transport was nearly an order of magnitude greater than that for MeAIB and the initial rate of accumulation was stimulated approximately eightfold by sodium ion. Qualitatively similar to the data for MeAIB transport, vesicles from rats treated with TNF exhibited a $45 \%$ increase in the initial rate of $\mathrm{Na}^{+}$-dependent glutamine uptake and a $30 \%$ stimulation in peak $\mathrm{Na}^{+}$-dependent accumulation at $1 \mathrm{~min}$ relative to vesicles from control animals (Fig. $1 \mathrm{~B}$ ). Equilibrium uptake values for vesicles from either experimental condition were highly comparable, indicating similar vesicular size. Intravesicular volumes calculated from equilibrium uptakes of MeAIB and glutamine were $0.59 \pm 0.19$ and $0.64 \pm 0.10 \mu \mathrm{l} / \mathrm{mg}$ protein for vesicles from control and TNFtreated rats, respectively.

The influence of time and the dose of TNF on hepatic amino acid transport activity were investigated in a series of experiments. In vesicles prepared from rats $4 \mathrm{~h}$ after injection, prior exposure to 50,150 , or $450 \mu \mathrm{g} / \mathrm{kg}$ TNF resulted in a dose-dependent 3.5- to 5.3-fold stimulation of the $\mathrm{Na}^{+}$-dependent transport of $50 \mu \mathrm{M}$ MeAIB (Fig. 2). To examine the time course of the response to TNF, rats were treated with $150 \mu \mathrm{g} /$ $\mathrm{kg}$ TNF and vesicles prepared 2, 4, and $24 \mathrm{~h}$ later for examination of MeAIB and glutamine transport activity. As shown in Fig. $3 \mathrm{~A}$, vesicles from rats exposed to TNF for $2 \mathrm{~h}$ exhibited a 

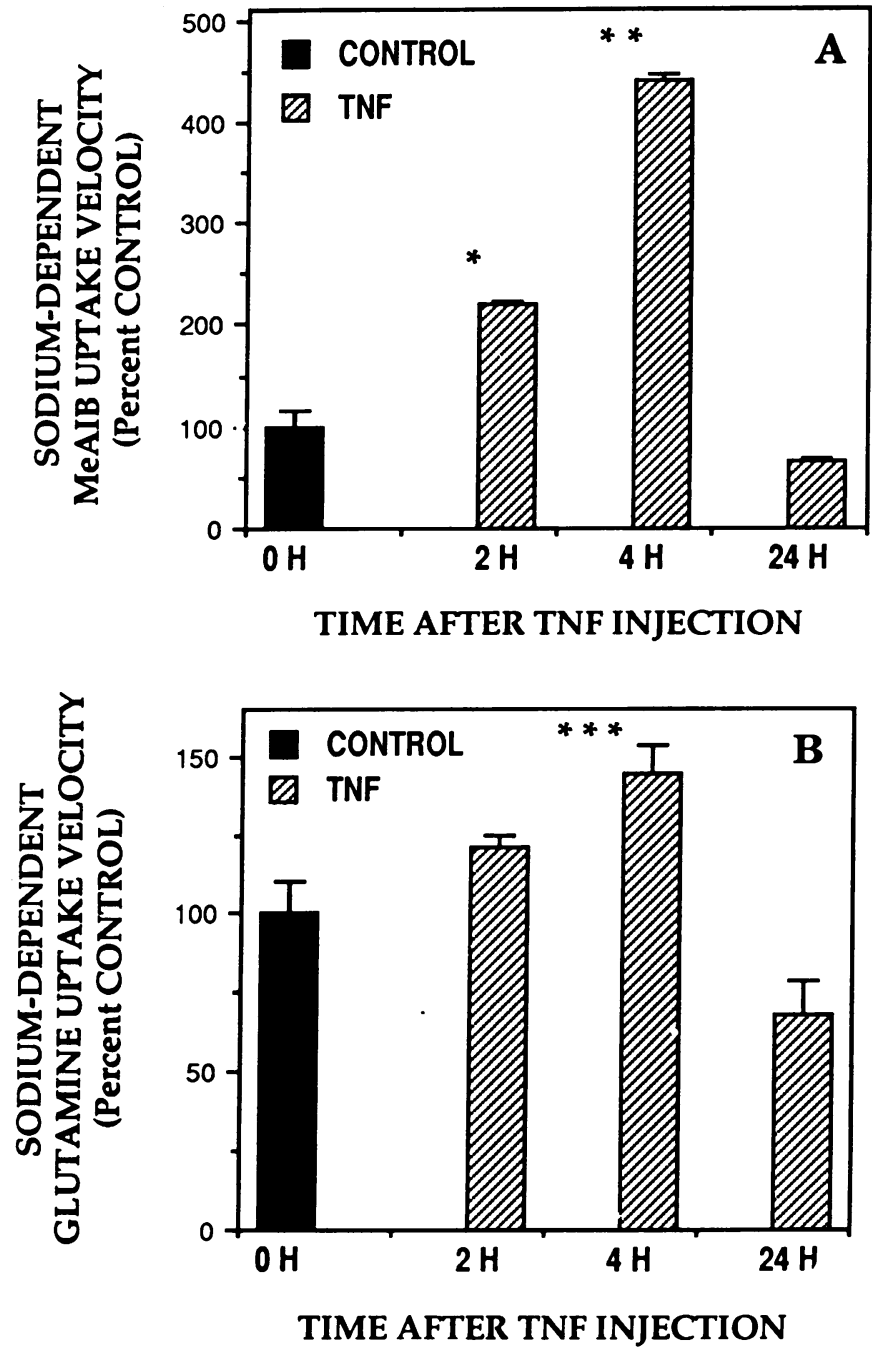

Figure 3. Effect of time on TNF-stimulated amino acid transport by HPMVs prepared from Control and TNF-treated rats. Rats were treated with vehicle (control) or TNF $(150 \mu \mathrm{g} / \mathrm{kg})$. HPMVs were prepared 2,4 , and $24 \mathrm{~h}$ later and the 10 -s $\mathrm{Na}^{+}$-dependent uptake of $50 \mu \mathrm{M}\left[{ }^{3} \mathrm{H}\right] \mathrm{MeAIB}(A)$ or $100 \mu \mathrm{M}\left[{ }^{3} \mathrm{H}\right]$ glutamine $(B)$ was determined as described in Methods. Actual control values (mean \pm SEM) for uptake are $7.4 \pm 1.2$ and $171.1 \pm 17.4 \mathrm{pmol} / \mathrm{mg}$ protein $10 \mathrm{~s}$ for MeAIB and glutamine, respectively. $P<0.001 *$ vs. Control, ${ }^{* *}$ vs. 2 $\mathrm{h} ;{ }^{* * *} P<0.01$ vs. Control.

greater than twofold increase in the $\mathrm{Na}^{+}$-dependent transport of $50 \mu \mathrm{M}$ MeAIB. Sodium-dependent MeAIB transport was further stimulated more than fourfold over control values at 4 $h$ but had returned to basal levels $24 \mathrm{~h}$ after TNF administration. The time course of the TNF-induced stimulation of $\mathrm{Na}^{+}$dependent glutamine transport by vesicles followed a similar pattern, although the relative changes were not as marked as those observed for MeAIB (Fig. $3 \mathrm{~B}$ ). The $\mathrm{Na}^{+}$-dependent uptake of $100 \mu \mathrm{M}$ glutamine exhibited a trend towards a $21 \%$ increase over controls by $2 \mathrm{~h}$ and was significantly increased $44 \%$ by $4 \mathrm{~h}$. Preparation of vesicles $24 \mathrm{~h}$ after TNF treatment resulted in glutamine uptake by hepatic vesicles that was indistinguishable from that observed in vesicles from untreated animals.

Pooled transport data from multiple vesicle preparations from control rats and rats treated with $150 \mu \mathrm{g} / \mathrm{kg}$ TNF for $4 \mathrm{~h}$ demonstrated the effect of TNF on the $\mathrm{Na}^{+}$-dependent and $\mathrm{Na}^{+}$-independent transport of $50 \mu \mathrm{M}$ MeAIB, $100 \mu \mathrm{M}$ glutamine, and $100 \mu \mathrm{M}$ cysteine in the presence of $10 \mathrm{mM}$ MeAIB (Fig. 4). In vesicles prepared from rats $4 \mathrm{~h}$ after injection of TNF, the activity of hepatic plasma membrane amino acid transport systems A (Fig. $4 A$ ), N (Fig. $4 B$ ), and ASC (Fig. 4 $C$ ) were increased 5.3 -fold, $47 \%$, and $80 \%$, respectively, relative to untreated controls. In contrast, the $\mathrm{Na}^{+}$-independent transport of these amino acids was unaffected by prior treatment with TNF.

Because of the observation that the MeAIB transport data indicated such a profound TNF-induced response of hepatic system $A$ and because system $A$ is capable of catalyzing the $\mathrm{Na}^{+}$-dependent transport of most neutral amino acids to a greater or lesser degree $(10,13)$, we wished to examine the transport of MeAIB, glutamine, and cysteine by vesicles in the absence and presence of an excess of unlabeled MeAIB to competitively block system A (Fig. 5). As would be expected, competitively blocking system A with unlabeled MeAIB resulted in 95\% inhibition of radiolabeled MeAIB uptake and abrogated the marked TNF-induced increase in uptake observed in the absence of system A blockade (Fig. $5 \mathrm{~A}$ ). The presence of 10 $\mathrm{mM}$ MeAIB resulted in 65 to $70 \%$ inhibition of the vesicular uptake of cysteine, an amino acid known to be an acceptable substrate for both systems A and ASC (Fig. $5 \mathrm{~B}$ ). The near threefold TNF-induced increase in cysteine transport observed in the absence of MeAIB (via both system A and system ASC) was reflected by the retention of a 1.4-fold increase in transport when uptake was undertaken in the presence of MeAIB (i.e., the system ASC component alone; see also Fig. $4 C$ ). In contrast, as shown in Fig. $5 C$, MeAIB was much less effective at inhibiting the $\mathrm{Na}^{+}$-dependent uptake of glutamine, an amino acid restricted to a large extent to system $N$ in the liver (14). Inhibition of system $A$ by $10 \mathrm{mM}$ MeAIB resulted in an approximate $20 \%$ inhibition of $\mathrm{Na}^{+}$-dependent glutamine uptake and the TNF-induced increase in uptake observed in the absence of MeAIB (system N plus the modest contribution of system A) was retained in the presence of MeAIB (system $\mathrm{N}$ alone).

To investigate the increase in amino acid transport activity observed in vesicles from animals treated with TNF, kinetic transport experiments were undertaken. The initial rate of $\mathrm{Na}^{+}$-dependent MeAIB and glutamine uptake by vesicles from control and TNF-treated rats as a function of substrate concentration is shown in Figs. 6 and 7. $\mathrm{Na}^{+}$-dependent MeAIB uptake was significantly elevated in vesicles from TNF-treated rats at all extravesicular MeAIB concentrations (Fig. $6 \mathrm{~A}$ ). Eadie-Hofstee linear transformation of the data suggested the presence of both a high affinity and a low affinity $\mathrm{Na}^{+}$-dependent carrier, which was confirmed when the data were analyzed by nonlinear regression (Fig. $6 B, r=0.96$ and 0.92 , respectively). The total $\mathrm{Na}^{+}$-dependent velocity $(V)$ is the sum of the velocities of the two systems (27), as described mathematically below

$V_{\text {total }}=V_{\text {low }}+V_{\text {high }}=\frac{V_{\max }^{\mathrm{lo}}[\mathrm{MeAIB}]}{K_{\mathrm{m}}^{\mathrm{lo}}+[\mathrm{MeAIB}]}+\frac{V_{\max }^{\mathrm{hi}}[\mathrm{MeAIB}]}{K_{\mathrm{m}}^{\mathrm{hi}}+[\mathrm{MeAIB}]}$.

The curved line (TNF data) in Fig. $6 B$ is a plot of the empirical data, which is a composite of the two systems, indicated by the solid lines (Fig. $6 \mathrm{~B}$ ). The observed increase in uptake was due to a fourfold increase in the maximal velocity 

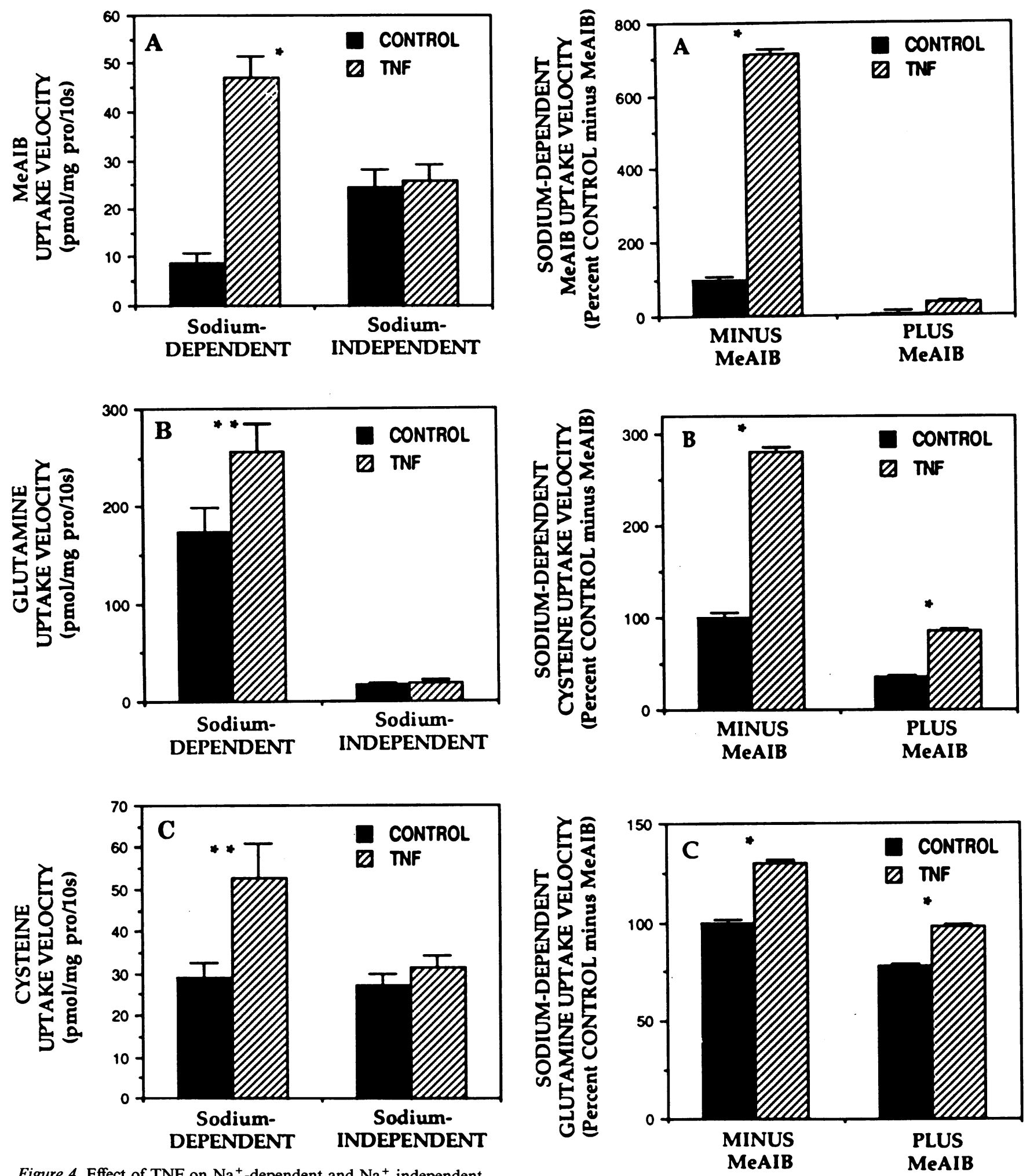

Figure 4. Effect of TNF on $\mathrm{Na}^{+}$-dependent and $\mathrm{Na}^{+}$-independent amino acid transport by HPMVs prepared from control and TNFtreated rats. Rats were treated with vehicle (control) or TNF ( 150 $\mu \mathrm{g} / \mathrm{kg}$ ) and HPMVs were prepared $4 \mathrm{~h}$ later. The $10-\mathrm{s} \mathrm{Na}^{+}$-dependent and $\mathrm{Na}^{+}$-independent uptakes of $50 \mu \mathrm{M}\left[{ }^{3} \mathrm{H}\right] \mathrm{MeAIB}(A), 100 \mu \mathrm{M}$ $\left[{ }^{3} \mathrm{H}\right]$ glutamine $(B)$, and $100 \mu \mathrm{M}\left[{ }^{35} \mathrm{~S}\right]$ cysteine $(C)$ were determined as described in Methods. Data shown for cysteine reflects uptake in the presence of $5 \mathrm{mM}$ DTT and $10 \mathrm{mM}$ unlabeled MeAIB. Each determination represents the mean \pm SEM of vesicle preparations from 7 to 11 animals. ${ }^{*} P<0.001$ vs. Control, ${ }^{* *} P<0.05$ vs. Control.

Figure 5. Influence of MeAIB inhibition of system A on amino acid transport by HPMVs prepared from control and TNF-treated rats. Rats were treated with vehicle (control) or TNF $(150 \mu \mathrm{g} / \mathrm{kg})$ and HPMVs were prepared $4 \mathrm{~h}$ later. The 10 -s $\mathrm{Na}^{+}$-dependent uptake of $50 \mu \mathrm{M}\left[{ }^{3} \mathrm{H}\right] \mathrm{MeAIB}(A), 100 \mu \mathrm{M}\left[{ }^{35} \mathrm{~S}\right]$ cysteine $(B)$, and $100 \mu \mathrm{M}$ $\left[{ }^{3} \mathrm{H}\right]$ glutamine $(C)$ were determined as described in Methods in the absence and presence of a $10 \mathrm{mM}$ excess of unlabeled MeAIB to block any system $\mathrm{A}$-mediated transport component. ${ }^{*} P<0.001$ vs. corresponding Control. 

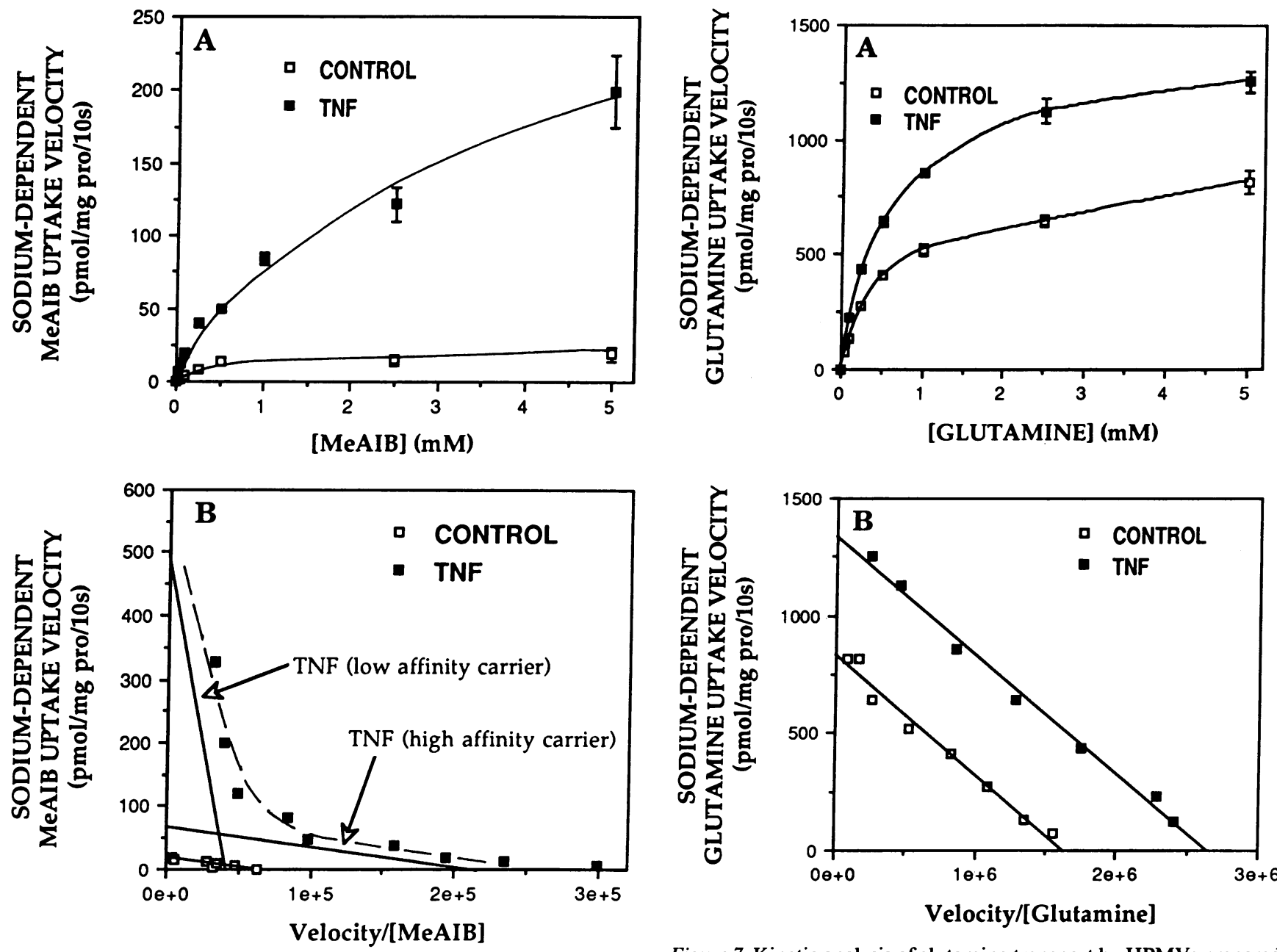

Figure 6. Kinetic analysis of MeAIB transport by HPMVs prepared from control and TNF-treated rats. Rats were treated with vehicle (control) or TNF $(150 \mu \mathrm{g} / \mathrm{kg})$ and HPMVs were prepared $4 \mathrm{~h}$ later. $(A)$ The 10 -s $\mathrm{Na}^{+}$-dependent uptake of $\left[{ }^{3} \mathrm{H}\right] \mathrm{MeAIB}$ was determined as described in Methods across increasing initial extravesicular MeAIB concentrations. $(B)$ Eadie-Hofstee linear transformation of $\mathrm{Na}^{+}$-dependent MeAIB transport. MeAIB uptake velocity was plotted as a function of velocity/substrate concentration. Regression analysis of the data revealed two transport systems with markedly different affinities $\left(K_{\mathrm{m}}=\right.$ negative slopes $)$ and maximal transport velocities $\left(V_{\max }=y\right.$-intercepts $)$.

of high affinity transport $\left(V_{\max } ; 17.82\right.$ in control vs. 71.91 $\mathrm{pmol} / \mathrm{mg}$ protein per $10 \mathrm{~s}$ in TNF) with little alteration in transporter affinity $\left(K_{\mathrm{m}} ; 278\right.$ in control vs. $315 \mu \mathrm{M}$ in TNF; Fig. $6 \mathrm{~B}$ ). In addition, we consistently observed a second, low affinity MeAIB transport component in vesicles from rats treated with TNF $\left(K_{\mathrm{m}}=12.37 \mathrm{mM}, V_{\max }=495 \mathrm{pmol} / \mathrm{mg}\right.$ protein per $10 \mathrm{~s}$ ) that was not apparent in controls and contributed to the increase in MeAIB uptake at higher substrate concentrations. Under specific conditions, such kinetic heterogeneity of system A-mediated transport has been observed previously by other investigators $(28,29)$. Similarly, $\mathrm{Na}^{+}$-dependent glutamine transport was increased in vesicles from TNFtreated rats across all assay glutamine concentrations (Fig. 7 $A$ ). Regression analysis of Eadie-Hofstee linear transformation of the data indicated that the increase was due to a $61 \%$ increase in the transport $V_{\max }(834$ in control vs. $1,339 \mathrm{pmol} / \mathrm{mg}$ pro-

Figure 7. Kinetic analysis of glutamine transport by HPMVs prepared from control and TNF-treated rats. Rats were treated with vehicle (control) or TNF $(150 \mu \mathrm{g} / \mathrm{kg})$ and HPMVs were prepared $4 \mathrm{~h}$ later. $(A)$ The $10-\mathrm{s} \mathrm{Na}^{+}$-dependent uptake of $\left[{ }^{3} \mathrm{H}\right]$ glutamine was determined as described in Methods and Fig. 6. $(B)$ Eadie-Hofstee linear transformation of $\mathrm{Na}^{+}$-dependent glutamine transport.

tein per $10 \mathrm{~s}$ in TNF) without alteration of the $K_{\mathrm{m}}(0.51 \mathrm{mM}$ for both control and TNF) for a kinetically homogeneous population of transporters (Fig. $7 \mathrm{~B}$ ).

Despite the observations demonstrating increases in the activity of $\mathrm{Na}^{+}$-dependent hepatic plasma membrane transport secondary to TNF administration, this was not reflected upon examination of carrier-mediated $\mathrm{Na}^{+}$-independent transport. The saturable, carrier-mediated component of $\mathrm{Na}^{+}$-independent leucine and glutamine transport by vesicles accounted for $\sim 40-45 \%$ of the total $\mathrm{Na}^{+}$-independent uptake (the remainder being nonsaturable uptake, i.e., diffusion or a very high $K_{\mathrm{m}}$ system). In contrast to $\mathrm{Na}^{+}$-dependent transport, prior treatment of animals with TNF did not result in any alterations in the saturable, $\mathrm{Na}^{+}$-independent uptake of leucine or glutamine (Fig. 8).

Effects of TNF on sodium transport in HPMVs. The transport of sodium by HPMVs from animals treated with TNF ( $150 \mathrm{mg} / \mathrm{kg}$ ) was not different from sodium transport by HPMVs prepared from control rats (Fig. 9). In vesicles from 


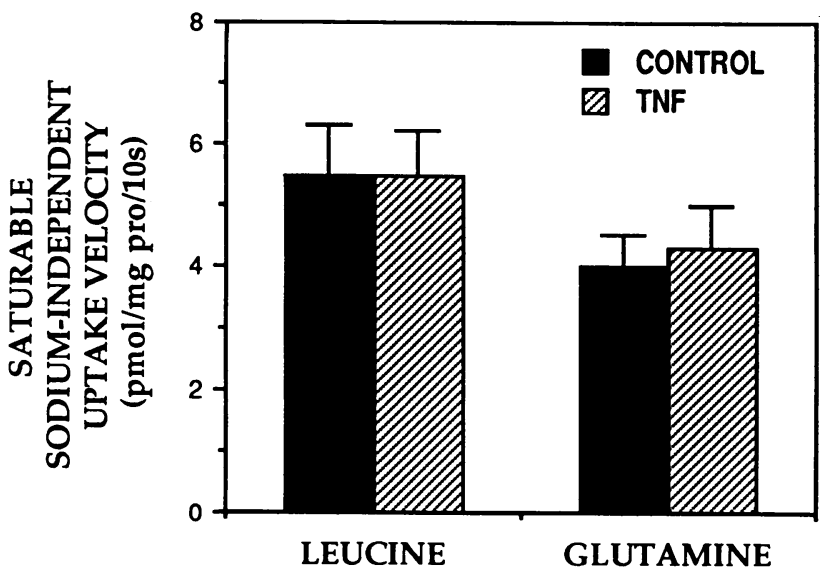

Figure 8. System L-mediated $\mathrm{Na}^{+}$-independent leucine transport and saturable $\mathrm{Na}^{+}$-independent glutamine transport by HPMVs prepared from control and TNF-treated rats. Rats were treated with vehicle (control) or TNF $(150 \mu \mathrm{g} / \mathrm{kg})$ and HPMVs were prepared $4 \mathrm{~h}$ later. The saturable, system $\mathrm{L}$-mediated $\mathrm{Na}^{+}$-independent uptake of 50 $\mu \mathrm{M}\left[{ }^{3} \mathrm{H}\right]$ leucine was determined in the absence of $\mathrm{Na}^{+}$and in the absence or presence of $10 \mathrm{mM} \mathrm{BCH}$ as described in Methods. The saturable, $\mathrm{Na}^{+}$-independent uptake of $50 \mu \mathrm{M}\left[{ }^{3} \mathrm{H}\right]$ glutamine was similarly determined in the absence of $\mathrm{Na}^{+}$and in the absence and presence of $10 \mathrm{mM}$ excess unlabeled glutamine.

both control and TNF-treated rats, sodium uptake increased as a function of time of incubation.

Amino acid transport in HPMVs incubated with cytokines. Incubation of HPMVs prepared from normal rats with two different concentrations of TNF, IL-1, or IL-6 in vitro did not alter $\mathrm{Na}^{+}$-dependent transport of glutamine, MeAIB, or cysteine (Fig. 10).

Effects of the glucocorticoid antagonist $R U$ 38486. Pretreatment of rats with the glucocorticoid antagonist RU 38486 resulted in a $40-50 \%$ reduction in the TNF-stimulated increase in $\mathrm{Na}^{+}$-dependent amino acid transport activity (Fig. 11). In contrast, rats receiving the gavage solution containing only vehicle demonstrated no attenuation of the TNF-induced increase in transport activity. Kinetic studies demonstrated that the steroid antagonist decreased transporter $V_{\max }$ rather than carrier affinity (the $y$-intercept was diminished but the slope of the lines were unchanged).

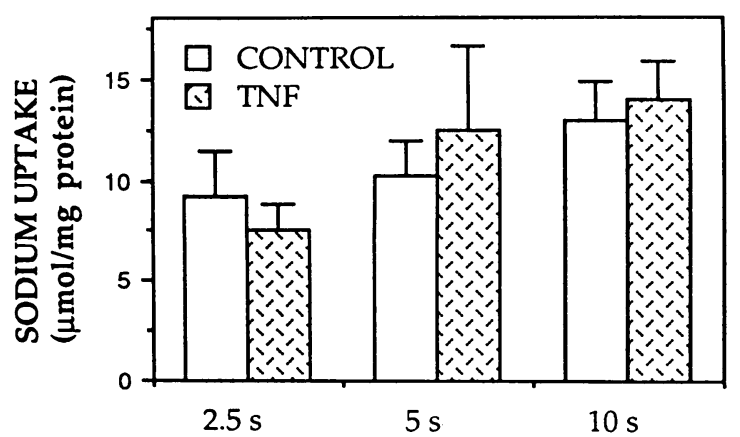

Figure 9. Sodium transport by HPMVs from control and TNF-treated rats. Rats were treated with vehicle (control) or TNF $(150 \mu \mathrm{g} / \mathrm{kg})$ and HPMVs were prepared $4 \mathrm{~h}$ later. The transport of sodium was assayed as described in Methods. Each determination represents the mean \pm SEM of quadruplicate vesicle preparations from three animals.
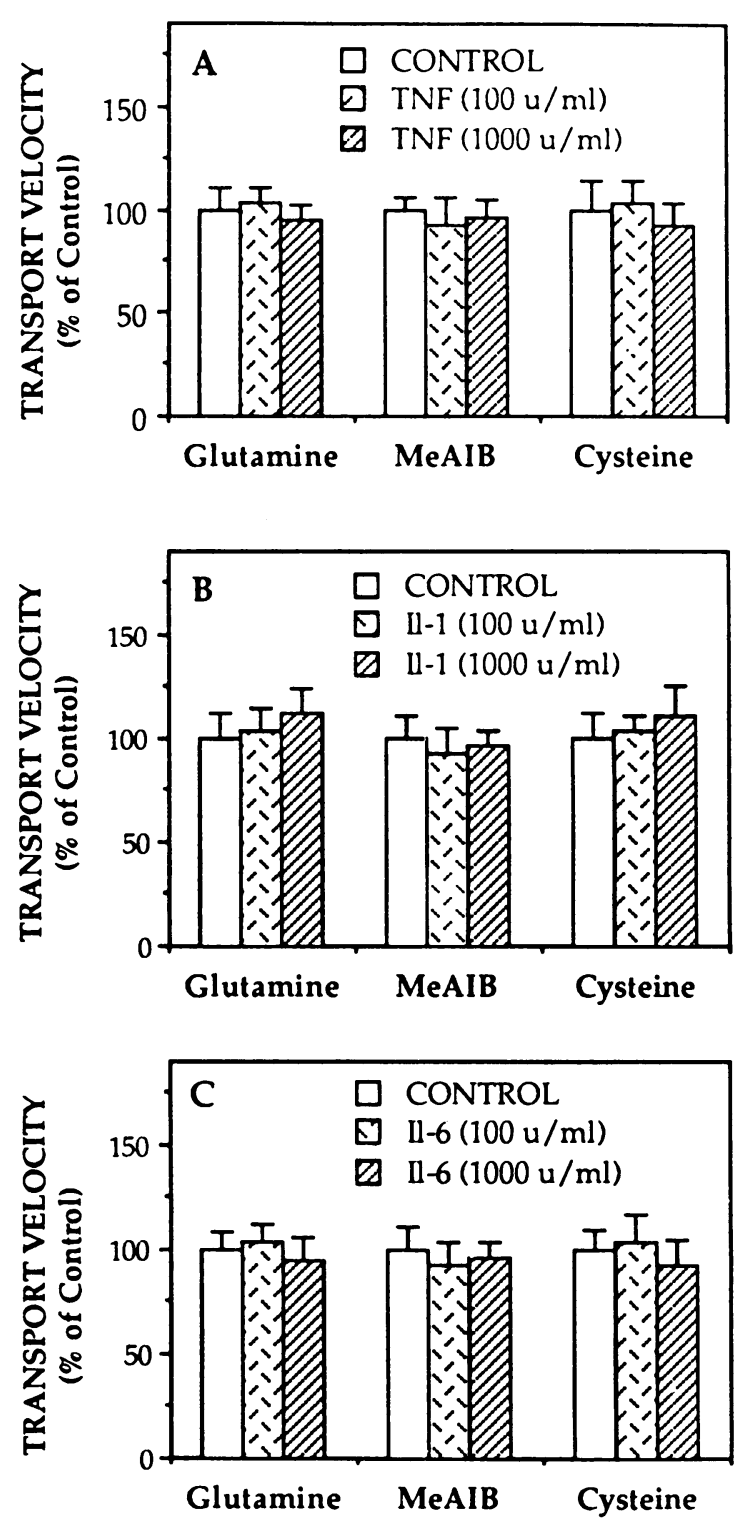

Figure 10. Amino acid transport in HPMVs incubated with TNF, IL-1, and IL-6. HPMVs prepared from the livers of normal rats were incubated in vitro for $1 \mathrm{~h}$ with two different concentrations of TNF $(A)$, IL-1 $(B)$, and IL-6 $(C)\left(100\right.$ and $1,000 \mathrm{U} / \mathrm{ml}, 1 \mu \mathrm{g}=3 \times 10^{5}$ $\mathrm{U})$ or vehicle (controls). The $10-\mathrm{s} \mathrm{Na}^{+}$-dependent uptake of radiolabeled amino acids was determined as described in Methods. Each determination represents the mean \pm SEM of two separate experiments each done in triplicate.

\section{Discussion}

TNF has been identified as one of the primary mediators of the spectrum of physiological alterations that characterize severe injury and infection (4-7). Among the constellation of metabolic alterations that occur during sepsis, the mobilization of amino acids from the periphery and the concomitant acceleration of hepatic amino acid uptake are of key significance. This augmented amino acid uptake by the liver serves to support hepatic gluconeogenesis and acute-phase protein synthesis and has important survival implications $(1,3)$.

Consistent with the observation that TNF can mimic many of the manifestations of sepsis, previous studies have demon- 

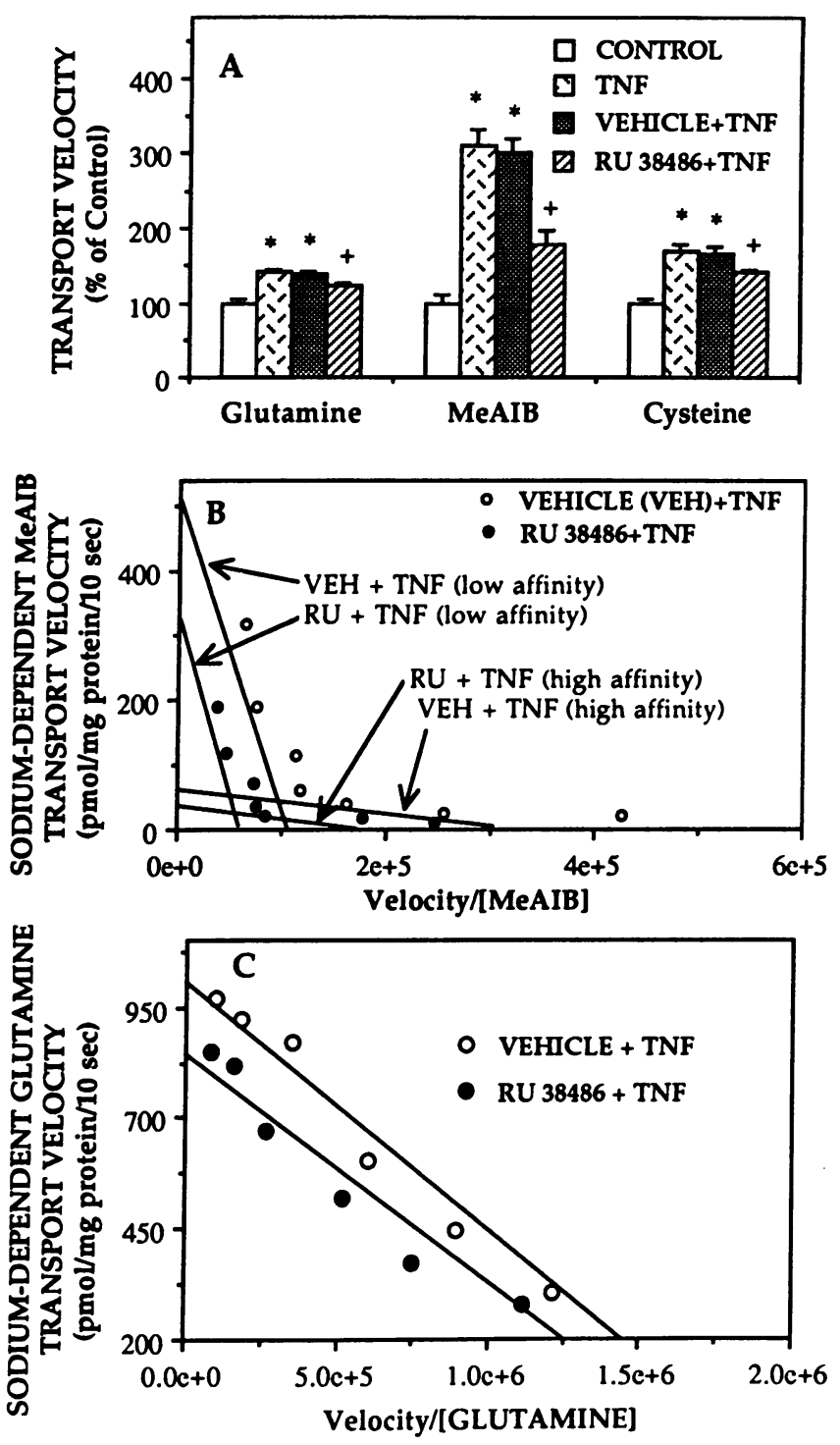

Figure 11. Effects of RU 38486 on $\mathrm{Na}^{+}$-dependent amino acid transport by HPMVs prepared from control or TNF-treated rats. $(A)$ As described in Methods, one group of TNF-treated animals received RU 38486 by gavage before TNF administration whereas second group was pretreated with vehicle. HPMVs were prepared $4 \mathrm{~h}$ after TNF administration and the 10 -s $\mathrm{Na}^{+}$-dependent uptake of $100 \mu \mathrm{M}$ radiolabeled amino acids was determined as described in Methods. Mean control glutamine uptake $=105 \mathrm{pmol} / \mathrm{mg}$ protein per $10 \mathrm{~s}$; mean control MeAIB uptake $=7 \mathrm{pmol} / \mathrm{mg}$ protein per $10 \mathrm{~s}$; mean cysteine uptake (in the presence of $10 \mathrm{mM}$ cold MeAIB) $=35 \mathrm{pmol} /$ mg protein per $10 \mathrm{~s}$. $(B)$ Treatment with RU 38486 diminished the $V_{\max }$ of both the low affinity and high affinity system A carrier induced by endotoxin. $(C)$ Pretreatment with the glucocorticoid receptor antagonist also decreased the $V_{\max }$ of glutamine transport. Each determination represents the mean \pm SEM of quadruplicate vesicle preparations from two to four animals. ${ }^{*} P<0.01$ vs. control, ${ }^{* *} P$ $<0.05$ vs. all groups.

strated stimulation of amino acid uptake by liver secondary to administration of TNF, with an emphasis on the uptake of substrates assigned to the A system (12-18). However, studies investigating cytokine modulation of hepatic carrier-mediated amino acid transport directly at the cellular or membrane level to examine the participation of distinct transport agencies in this response have been sparse. In the present investigation we have used isolated HPMVs to more thoroughly examine the modulation of hepatic $\mathrm{Na}^{+}$-dependent systems $\mathrm{A}, \mathrm{ASC}$, and $\mathrm{N}$, as well as $\mathrm{Na}^{+}$-independent transport processes, by TNF. Membrane vesicles prepared from whole liver have been used with success in the past by our laboratory (20) and by others $(30,31)$ to examine amino acid transport and they offer the unique advantage of discriminating membrane transport activity free from other confounding influences (e.g., alterations in blood flow and or clearance, intracellular metabolism, trans-effects, etc.). Additionally, alterations in membrane transport activity occurring in intact hepatocytes are retained during the preparation of vesicles (31).

Our data demonstrate that in vivo administration of a single dose of TNF results in time- and dose-dependent increases in the activity of the principal amino acid transport systems present in the hepatocyte plasma membrane and that these changes are transient, recovering to the basal state within $24 \mathrm{~h}$ of the cytokine challenge. One would expect such an increase in membrane transporters to be reflected at the intact whole organ level as an accelerated uptake of amino acids. The observations of Warren et al. (18), showing a dose-dependent fivefold maximal increase in the hepatic distribution ratio of AIB (a less selective system A substrate relative to its methylated derivative, MeAIB) $4 \mathrm{~h}$ after TNF administration to rats, are highly consistent with our results. We have demonstrated that TNF treatment results in a fourfold increase in the maximal velocity of high affinity hepatic system A-mediated transport. In addition, we observed the appearance of a second low affinity system A transport component not observed in control animals. This dichotomy in system A-mediated transport has been observed by others $(28,29)$, particularly under conditions derepressing system $\mathrm{A}$, such as amino acid starvation and cellular transformation (28). Such a TNF-induced heterogeneity in system A transport may translate into an additional augmentation of hepatic amino acid uptake in vivo during sepsis.

System A accepts virtually all neutral amino acids as substrates, with a preference towards the smaller neutral amino acids, such as alanine $(8,10,29)$, which is one of the principal amino acids released by muscle and taken up by liver during sepsis $(1,32)$. Thus, the marked severalfold increase in the activity of system $\mathrm{A}$ we observed is consistent with previous flux data demonstrating increased hepatic alanine (13) and AIB $(12,17,18)$ consumption in response to TNF. Increased system A activity would preferentially support hepatic gluconeogenesis from alanine, in addition to augmenting overall amino acid uptake for acute-phase protein synthesis.

Similarly, system ASC is a transport agency having a broad amino acid selectivity with a preference towards alanine, serine, and cysteine $(8,10,29)$. Our observation of substantial inhibition of cysteine transport in the presence of system A-saturating concentrations of MeAIB is consistent with the fact that cysteine is accepted by both systems A and ASC. It is also clear from our data that the hepatic membrane transport of cysteine is accelerated in response to TNF, not only secondary to an increase in the activity of system $A$, demonstrated in the present report and suggested by studies mentioned previously, but also by an $80 \%$ increase in the activity of hepatic amino acid transport system ASC itself (see Fig. $4 C$ and Fig. $5 B$ ).

Unlike systems A and ASC, system $\mathrm{N}$ is found only in hepatic tissue and does not possess a broad substrate selectivity, being largely restricted to the mediated transport of glutamine and related amino acid amides (11). Accordingly, the $\mathrm{Na}^{+}$-dependent transport of glutamine is to a large extent an index of 
the activity of system $N$. In our vesicle preparations this was further validated by the marginal influence of system A blockade on glutamine uptake in vesicles from either control or TNF-treated animals. Glutamine, like alanine, occupies a central role in interorgan amino acid metabolism (32) and is profoundly affected by critical illness (33). During severe infection the liver becomes the principal organ of glutamine uptake (32). Our data demonstrate that TNF induces a 50\% increase in hepatic glutamine transport, and that this is a consequence of a real increase in system $\mathrm{N}$ activity and not merely residual augmentation secondary to the marked increase in system $\mathrm{A}$. This suggests that cytokine-mediated alterations in the activity of hepatic system $\mathrm{N}$ may play a major role in redirecting glutamine flow during sepsis and support glutamine using processes in the liver.

In contrast to the in vivo results discussed above, incubation of HPMVs from normal animals in vitro with TNF, IL-1, or IL-6 did not alter $\mathrm{Na}^{+}$-dependent amino acid transport (Fig. 10 ), indicating that TNF-induced stimulation of amino acid uptake is not an event mediated by a direct action of TNF at the membrane surface (i.e., clustering of membrane proteins, changes in fluidity characteristics). Likewise, studies in cultured hepatocytes incubated with cytokines have failed to show an increase in amino acid transport at early time points. Incubation of hepatocytes from normal rats with IL-1 did not stimulate system A activity (16). Similarly, IL-6 does not appear to stimulate system $\mathrm{N}$ or system A activity acutely in hepatocytes (Dr. Souba, unpublished results), whereas chronic in vitro treatment $(48 \mathrm{~h})$ of cultured hepatocytes with IL-6 alone is capable of stimulating system A twofold (14). TNF does not stimulate amino acid transport in hepatocytes directly but does enhance the stimulation of amino acid transport by glucagon (17). These in vitro studies suggest that, at early time points, cytokines alone do not alter amino acid transport across the hepatocyte plasma membrane but may work through (or with) another mediator(s). TNF is capable of initiating the release of other cytokines such as IL-1 and IL-6 (6), which may modulate transport activity indirectly in the liver. In hepatocytes isolated from rats treated in vivo with IL-1, the rate of alanine uptake (systems A and ASC) was significantly increased over that seen in hepatocytes from control animals (16). TNF administration may also be accompanied by the release of hormonal mediators, such as glucagon and the glucocorticoid hormones, that are known to stimulate system A and system $\mathrm{N}$ (8, $10,34)$. Thus, these other cytokines may work together with hormones, such as the glucocorticoids, in an orchestrated fashion to control amino acid transport across the hepatocyte plasma membrane during critical illness.

To further investigate this possibility, in the current study we examined the role of the glucocorticoid hormones in the TNF-stimulated increase in hepatic amino acid transport using RU 38486. The dose of glucocorticoid antagonist used results in $\sim 90 \%$ blockade of glucocorticoid receptors in muscle (35). The effects of the glucocorticoid antagonist RU 38486 can probably be ascribed to its competition for the cytosolic glucocorticoid receptor and it has been reported that RU 38486 binds even more strongly to the glucocorticoid receptor in target tissues than do potent glucocorticoid agonists such as dexamethasone $(36,37)$. Pretreatment of rats with the glucocorticoid antagonist attenuated the TNF-stimulated increase in $\mathrm{Na}^{+}$-dependent amino acid transport by $\sim 50 \%$, consistent with a role for the glucocorticoid hormones in mediating a portion of the accelerated amino acid transport we observed.
This observation is important, particularly with regards to glutamine and cysteine, since it has previously been shown that a 4-h (the time point after TNF administration at which we observed the maximum increase in transport activity in HPMVs) incubation of isolated hepatocytes with the glucocorticoid derivative dexamethasone does not alter system $\mathrm{N}$ or system ASC transport activity $(11,38)$. Thus, the glucocorticoids may work synergistically with other mediators to regulate hepatic amino acid transport. Since RU 38486 did not abrogate the increase in transport that was cytokine-induced, it is likely that other hormones and cytokines also play a role in regulating the accelerated $\mathrm{Na}^{+}$-dependent amino acid uptake that occurs after TNF administration.

In contrast to the increases in $\mathrm{Na}^{+}$-dependent transport we observed, the carrier-mediated $\mathrm{Na}^{+}$-independent transport of leucine and glutamine was unaffected by TNF treatment. This difference in $\mathrm{Na}^{+}$-dependent and $\mathrm{Na}^{+}$-independent transport was not due to TNF alteration of cation transport since sodium transport by HPMVs from rats receiving TNF was not different from that in control vesicles. System $L$, for which leucine is a substrate, is thought to be relatively inert and in general plays a much greater role in mediating cellular amino acid exodus rather than entry $(8,39)$. It does, however, exhibit a high degree of "exchange" transport and as such may play a role in accelerated uptake in vivo secondary to elevations in intracellular amino acids brought about by stimulation of the concentrative $\mathrm{Na}^{+}$-dependent systems (29). Further, while we have data to suggest that $\mathrm{Na}^{+}$-independent glutamine transport is mediated by an agency distinct from system $\mathrm{L}$ (unpublished observations), it is clear that this process mediates the hepatic efflux, and not uptake, of glutamine (39).

The aforementioned studies represent a wealth of information relative to our understanding of the impact of TNF on the regulation of hepatic amino acid transport systems. The data indicate that TNF participates in a broad-based stimulation of the hepatocyte amino acid transport machinery. All three of the major $\mathrm{Na}^{+}$-dependent transport systems of the plasma membrane were affected in vivo, a response that was partly glucocorticoid mediated. Evaluation of the kinetic characteristics of this stimulation suggests that this is due to the appearance of increased numbers of the corresponding transporter proteins in the plasma membrane. This response of the hepatocyte transport machinery to TNF is not uniformly generalized, as the degree of stimulation varies depending upon the system examined and not every transport agency is affected. We suggest that the TNF-induced increases in the transport machinery of the hepatocyte are a key determinant underlying the marked acceleration of hepatic amino acid uptake that characterizes sepsis and serves to support vital amino acid requiring metabolic processes in the liver.

\section{Acknowledgments}

Supported by National Institutes of Health Grant CA 45327 and a grant from the Veteran Administration Merit Review Board.

\section{References}

1. Rosenblatt, S., G. H. A. Clowes, B. C. George, E. Hirsch, and B. Lindberg. 1983. Exchange of amino acids by muscle and liver in sepsis. Comparative studies in vivo and in vitro. Arch. Surg. 118:167-175.

2. Fong, Y., M. A. Morano, L. L. Moldawer, H. Wei, S. Calvano, J. S. Kenney, A. C. Allison, A. Cerami, T. Shires, and S. F. Lowry. 1990. The acute splanchnic and peripheral tissue metabolic response to endotoxin in humans. J. Clin. Invest 85:1896-1904. 
3. Clowes, G. H. A., E. Hirsch, B. C. George, L. Bigatello, J. Mazuski, and C. Villee. 1985. Survival from sepsis: the significance of altered protein metabolism regulated by proteolysis inducing factor, the circulating cleavage product of interleukin-1. Ann. Surg. 202:446-458.

4. Fraker, D. L., H. R. Alexander, and J. A. Norton. 1992. Biologic therapy of sepsis: the role of antibodies to endotoxin and tumor necrosis factor and the interleukin-1 receptor antagonist. In Biologic Therapy of Cancer. Vol. II. V. De Vita Jr., S. Hellman, and S. Rosenberg, editors. J. B. Lippincott Co., Philadelphia, 1-12.

5. Rock, C. S., and S. F. Lowry. 1991. Tumor necrosis factor- $\alpha$. J. Surg. Res. 51:434-445.

6. Fong, Y, K. J. Tracey, L. L. Moldawer, D. G. Hesse, K. B. Manogue, J. S. Kenney, A. T. Lee, G. C. Kuo, A. C. Allison, S. F. Lowry, et al. 1989. Antibodies to cachectin/tumor necrosis factor reduce interleukin $1 \beta$ and interleukin 6 appearance during lethal bacteremia. J. Exp. Med. 170:1627-1633.

7. Michie, H. R., K. R. Manogue, D. R. Spriggs, A. Revhaug, S. O'Dwyer, C. A. Dinarello, A. Cerami, S. Wolff, and D. W. Wilmore. 1988. Detection of circulating tumor necrosis factor after endotoxin administration. $N$. Engl. J. Med. 318:1481-1486.

8. Christensen, H. N. 1990. Role of amino acid transport and countertransport in nutrition and metabolism. Physiol. Rev. 70:43-77.

9. Collarini, E. J., and D. L. Oxender. 1987. Mechanisms of transport of amino acids across membranes. Annu. Rev. Nutr. 7:75-90.

10. Kilberg, M. S. 1982. Amino acid transport in isolated rat hepatocytes. $J$. Membr. Biol. 69:1-12.

11. Kilberg, M. S., M. E. Handlogten, and H. N. Christensen. 1980. Characteristics of an amino acid transport system in rat liver for glutamine, asparagine, histidine, and closely related analogs. J. Biol. Chem. 255:4011-4019.

12. Argiles, J. M., F. J. Lopez-Soriano, D. Wiggins, and D. H. Williamson. 1989. Comparative effects of tumour necrosis factor- $\alpha$ (cachectin), interleukin$1-\beta$ and tumour growth on amino acid metabolism in the rat in vivo. Biochem. J. 261:357-362.

13. Argiles, J. M., and F. J. Lopez-Soriano. 1990. The effects of tumour necrosis factor- $\alpha$ (cachectin) and tumour growth on hepatic amino acid utilization in the rat. Biochem. J. 266:123-126.

14. Bereta, J., A. Kurdowska, A. Koj, T. Hirano, T. Kishimoto, J. Content W. Fiers, J. Van Damme, and J. Gauldie. 1989. Different preparations of natural and recombinant human interleukin-6 (IFN- $\beta_{2}$, BSF-2) similarly stimulate acute phase protein synthesis and uptake of $\alpha$-aminoisobutyric acid by cultured rat hepatocytes. Int. J. Biochem. 21:361-366.

15. Bereta, J., K. Szuba, W. Fiers, J. Gauldie, and A. Koj. 1990. Transforming growth factor- $\beta$ and epidermal growth factor modulate basal and interleukin-6induced amino acid uptake and acute phase protein synthesis in cultured rat hepatocytes. FEBS. (Fed. Eur. Biochem. Soc.) Lett. 266:48-50.

16. Roh, M. S., L. L. Moldawer, L. G. Ekman, C. A. Dinarello, B. R. Bistran, M. Jeevanandam, and M. F. Brennan. 1986. Stimulatory effect of interleukinupon hepatic metabolism. Metabolism. 35:419-424.

17. Warren, R. S., D. B. Donner, H. F. Starnes, Jr., and M. F. Brennan. 1987 Modulation of endogenous hormone action by recombinant human tumor necrosis factor. Proc. Natl. Acad. Sci. USA. 84:8619-8622.

18. Warren, R. S., H. F. Starnes, Jr., N. Alcock, S. Calvano, and M. F. Brennan. 1988. Hormonal and metabolic response to recombinant human tumor necrosis factor in rat: in vitro and in vivo. Am. J. Physiol. 255:E206-E212.

19. Prpic, V., K. Green, P. Blackmore, and J. Exton. 1984. Vasopressin, angiotensin II, and alpha-adrenergic-induced inhibition of $\mathrm{Ca}^{++}$transport by rat liver plasma membrane vesicles. J. Biol. Chem. 259:1382-1385.
20. Pacitti, A. J., T. R. Austgen, and W. W. Souba. 1991. Adaptive regulation of alanine transport in hepatic membrane vesicles (HPMVs) from the endotoxintreated rat. J. Surg. Res. 51:46-53.

21. Moore, D. J. 1971. Enzyme purification and related techniques. Methods Enzymol. 22:130-148.

22. Swanson, M. A. 1955. Glucose-6-phosphatase from liver. Methods Enzymol. 2:541-543.

23. Kilberg, M. S., and H. N. Christensen. 1979. Electron transferring enzymes in the plasma membrane of the Ehrlich ascites tumor cell. Biochem. J. 18:1525-1530.

24. Fiske, C. H., and Y. Subbarow. 1925. The colorimetric determination of phosphorus. J. Biol. Chem. 66:375-400.

25. Bensadoun, A., and D. Weinstein. 1976. Assay of proteins in the presence of interfering materials. Anal. Biochem. 70:241-250.

26. Hall-Angeras, M., U. Angeras, O. Zamir, P. O. Hasselgren, and J. E. Fischer. 1991. Effect of the glucocorticoid receptor antagonist RU 38486 on muscle protein breakdown in sepsis. Surgery (St. Louis). 109:468-473.

27. Segel, I. H. Biochemical Calculations. 2nd edition. John Wiley and Sons, New York.

28. Boerner, P., and M. H. Saier II. 1985. Adaptive regulatory control of system A transport activity in a kidney epithelial cell line (MDCK) and in a transformed variant (MDCK-T1). J. Cell. Physiol. 122:308-315.

29. Christensen, H. N., and M. S. Kilberg. 1987. Amino acid transport across the plasma membrane: role of regulation in interorgan flows. In Amino Acid Transport in Animal Cells. D. Yudilevich, and C. Boyd, editors. Manchester University Press, Manchester, U.K. 10-176.

30. Jacob, R., N. Rosenthal, and E. J. Barrett. 1986. Characterization of glutamine transport by liver plasma membrane vesicles. Am. J. Physiol. 251:E509-E514.

31. Schenerman, M. A., and M. S. Kilberg. 1986. Maintenance of glucagonstimulated system $\mathrm{A}$ amino acid transport activity in rat liver plasma membrane vesicles. Biochim. Biophys. Acta. 856:428-436.

32. Austgen, T. R., M. K. Chen, T. C. Flynn, and W. W. Souba. 1991. The effects of endotoxin on the splanchnic metabolism of glutamine and related substrates. J. Trauma. 31:742-752.

33. Souba, W. W. 1991. Glutamine: a key substrate for the splanchnic bed. Annu. Rev. Nutr. 11:285-308.

34. Gebhardt, R., and E. Kleemann. 1987. Hormonal regulation of amino acid transport system $\mathrm{N}$ in primary cultures of rat hepatocytes. Eur. J. Biochem. 16:339-344.

35. Konagaya, M., P. A. Bernard, and S. R. Max. 1986. Blockade of glucocorticoid receptor binding and inhibition of dexamethasone-induced muscle atrophy in the rat by RU 38486, a potent glucocorticoid antagonist. Endocrinology. 119:375-380.

36. Kalimi, M. 1987. Receptor-mediated antiprogestin action of RU 486. In M. K. Agarwal, editor. Receptor-mediated Antisteroid Action. de Gruyter, Hawthorne, NY. 121-137.

37. Kalimi, M., and M. Argawal. 1988. Interaction of antiglucocorticoid RU 486 with rat kidney glucocorticoid receptor. Biochem. Biophys. Res. Commun. 153:365-371.

38. Kilberg, M. S., M. E. Handlogten, and H. S. Christensen. 1981. Characteristics of system ASC for transport of neutral amino acids in the isolated rat hepatocyte. J. Biol. Chem. 256:3304-3312.

39. Bode, B., B. K. Tamarappoo, M. Mailliard, and M. S. Kilberg. 1990. Characteristics and regulation of hepatic glutamine transport. J. Parenter. Enteral Nutr. 14(Suppl.):51S-55S. 